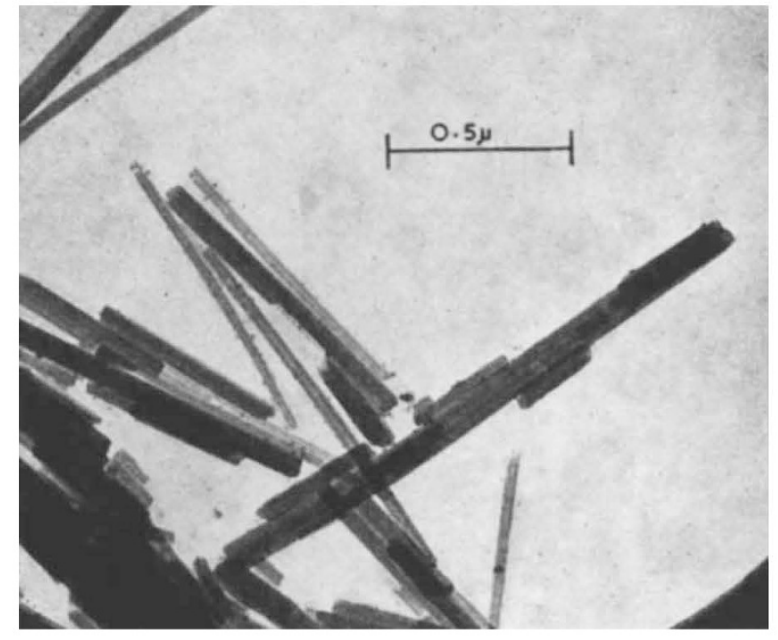

Fig. 3. Electron micrograph of a standard sample of chrysotile astestos $(\times c .36,600)$.

The purpose of this communication is to report factual observations; the clinical importance of those findings cannot as yet be assessed.

We thank Mr F. Raveney for technical assistance.

B. BILES

T. R. EMERSON

MRC Air Pollution Research Unit,

St Bartholomew's Hospital Medical College,

London.

Received May 13; revised May 31, 1068.

1 Problems Arising from the Use of Asbestos, Ministry of Labour, HM Factory Inspectoratc (HMSO, London, 1967).

${ }^{2}$ Hodgson, A. A., in Fibrous Silicates, Royal Institute of Chemistry, London, Lecture Ser., No. 4, 10 (1965).

s Whittaker, E. J. W., and Zussman, J., Min. Mag., 81, 107 (1956).

\section{Factors in the Design of Electrochemical Reactors}

THE purpose of this communication is to consider those factors which are important in tho design of reactors for electrosynthesis. This has become necessary because recent publications ${ }^{1-3}$ have given incomplete consideration to the problem. We shall ignore situations where the reactant is gaseous, thus avoiding problems associated with three phase boundaries.

The following points deserve consideration in the industrial scale-up of a laboratory process. (I) Probably the chief requirement is uniformity of the potential difference of the electrode solution over the entire electrode surface. If this parameter lics outside certain limits, then undesirable reactions will occur, resulting in wastage of power and probably of material. Furthormore, if activation control pertains, then a non-uniformity over the surface-typically more than $0.1 \mathrm{~V}$-causes a region of the electrode to remain essentially inactive. (2) A similar uniformity is required in the concentration of each species at the electrode interface. In many casss it will be necessary, in addition, to maintain the local concentrationdistanco profile into the solution. (3) Undesirable roactions may oceur if inadequate temperature control cxists throughout tho rcactor. (4) Power losses rosulting from Joule heating should be minimized. These can occur (a) within the electrode matcrials, (b) in the electrolyte and $(c)$ in the separator when one is used.

'The simplest electrochemical reactor is obviously two parallel plate electrodes, separated by a diaphragm, with agitation of the elcctrolytes. When the outward- facing sides of the electrodes are insulated from the solution, and provided that the separation distance is considerably smaller than the elcctrode dimensions, then the uniformity conditions (1)-(3) are satisfied. An exception exists whon the electrolytes aro pumped over the electrode and the reactant is significantly depleted during its passage through the cell.

This design is favoured when the real current densities at the electrode surface can be made sufficiently high $\left(>0 . \mathrm{I} \mathrm{A} \mathrm{cm}^{-2}\right)$. An upper limit exists for the current density through the diaphragm (usually of the order $1 \mathrm{~A} \mathrm{~cm}^{-2}$ ). High current densities require high rates of mass transfer; this is difficult to achievo for relatively insoluble substances $(<0 \cdot \mathbf{I} \mathrm{M})$.

In the case of reactions which sustain a current density which necessarily is much lower than $100 \mathrm{~mA} \mathrm{~cm}-2$ it is advantageous to adopt a three-dimensional electrode so that the current density through the diaphragm is signifcantly higher than that at the electrode surface. In this way the size and capital cost of the reactor can be kept to a minimum. In all three-dimensional electrodes, however, the uniformity of electrode potential cannot be maintained (also the uniformity of concentration is usually less easily maintained). Numerical calculations for both (a) activation and (b) concentration polarization within \& three-dimonsional electrode show that tho active volume of the elcctrode is essentially confined to a narrow region nearest to the auxiliary electrode when the conductivity of the electrode $\gg$ that of the electrolyte. For example, using the relations given by Newman and Tobias ${ }^{4}$, it follows that, in an activation controlled regime characterized by a Tafel slope of $100 \mathrm{mV}$ with an electrolyte effective specific conductance of $0.1 \mathrm{mho} \mathrm{cm}^{-1}$ when the diaphragm current density is $0 \cdot 1 \mathrm{~A} \mathrm{~cm}^{-2}, 50$ per cent of the reaction occurs within the first $0.2 \mathrm{~cm}$ of the electrode. The parameters used here relate to a favourable case. The thickness of the active region varies inversely with the diaphragm current density.

In the case of mass transfer controlled reactions the maximum thickness of the threc-dimensional electrode is given by $x_{\max }=\left(2 K \Delta E / \theta i_{d}\right)^{1 / 2}$, where $\Delta E$ is the potential variation which may be tolerated, $\theta$ is the elcetrode area per unit volume, $i_{d}$ the real electrode current density and $K$ the effective specific conductance of the electrolyte. When $K=0.1$ mho $\mathrm{cm}^{-1}, \Delta E=0.2 \mathrm{~V}, \theta=40 \mathrm{~cm}^{-1}$ and $i_{d}=10^{-3} \mathrm{~A} \mathrm{~cm}^{-2}$, then $x_{\max }=1 \mathrm{~cm}$. The values for $K$ and $\Delta E$ are optimistically high; those for $\theta$ and $i_{d}$ are attained readily in a well-designed flow cell provided that the reactant concentration exceeds $10^{-1} \mathrm{M}$.

Types of three-dimensional electrode which have been proposed are flooded-porous ${ }^{5}$, slurry ${ }^{6}$ and fluidized bed $^{1-3}$. In the last two cases even under conditions of moderate convection the problem of non-uniformity of electrode potential is seriously aggravated by the poor clectronic contact between particles in the electrode material ${ }^{7}$. It has been suggested that the fluidized bed electrode will be widely applicable in electrochemical engineering ${ }^{3}$. We conclude that scope for three-dimensional electrodes in general is restricted and that fluidized bed and slurry electrodes are expected to compare unfavourably with rigid three-dimensional configurations.
R. D. Armstrong
O. R. Brown
R. D. Grues
J. A. HARRISON

Department of Physical Chemistry,

University of Newcastle upon Tyne.

Received May 30, 1968.

${ }^{1}$ Backhurst, J. M., thesis, Univ, Newcastle upon Tyne (1967).

'British Patent Ápplication 23070/66.

${ }^{8}$ Goodridge, F., Chemical and Process Engineering, 49, 93 (1968).

- Newman, J. S., and Tobias, C. W., J. Electrochem. Soc., 109, 1183 (1962).

"Gurevich, I. G., and Bagotzky, V. S., Electrochim. Acta, 12, 593 (1967).

- Gerischer, H., Ber, Bunsen Ges, , B7, 164 (1963).

'Hiddleston, J. N., Nature,218, 601 (1068). 